\title{
openheart Contemporary use of excimer laser in percutaneous coronary intervention with indications, procedural characteristics, complications and outcomes in a university teaching hospital
}

\author{
Muhammad Jawad-UI-Qamar (1) ,,2 Harish Sharma (D) ,,2 \\ Vincenzo Vetrugno (1) , ${ }^{1,3}$ Kully Sandhu, ${ }^{1}$ Peter F Ludman (D) , ${ }^{1}$ Sagar N Doshi, ${ }^{1}$ \\ Jonathan N Townend, ${ }^{1}$ Mohammed Osheiba, ${ }^{1}$ Alex Zaphiriou, ${ }^{1}$ Sohail Q Khan (1) ${ }^{1,2}$
}

To cite: Jawad-UI-Qamar M, Sharma $\mathrm{H}$, Vetrugno V, et al. Contemporary use of excimer laser in percutaneous coronary intervention with indications, procedural characteristics, complications and outcomes in a university teaching hospital. Open Heart 2021;8:e001522. doi:10.1136/ openhrt-2020-001522

Received 20 December 2020 Revised 22 February 2021 Accepted 2 March 2021

Check for updates

(c) Author(s) (or their employer(s)) 2021. Re-use permitted under CC BY. Published by BMJ.

${ }^{1}$ Department of interventional cardiology, Queen Elizabeth Hospital Birmingham, Birmingham, UK ${ }^{2}$ Institute of Cardiovascular Sciences, University of Birmingham, Birmingham, UK ${ }^{3}$ Cardiology Division, Azienda Ospedaliero-Universitaria di Modena 0spedale Civile di Baggiovara, Modena, Italy

Correspondence to Dr Sohail Q Khan; sohail.khan@ uhb.nhs.uk

\section{ABSTRACT}

Background Excimer laser coronary atherectomy (ELCA) can be used as an adjunctive percutaneous coronary intervention treatment for challenging, heavily calcified lesions. Although previous studies have documented high rates of complication and restenosis, these predate the introduction of the smaller $0.9 \mathrm{~mm}$ laser catheter. As the coronary complexity has increased, there has been a renewed interest in the ELCA. This study investigates the indications, procedural characteristics, complications and outcomes of ELCA in a contemporary coronary interventional practice.

Methods This single-centre study retrospectively analysed 50 patients treated with ELCA between January 2013 and January 2019.

Results Patients had a mean age of $67.9 \pm 11.4$ years with a male predominance (65.3\%). 25 (50\%) cases were performed in patients with stable angina. Failure to deliver the smallest available balloon/ microcatheter was the most frequent indication in $32(64 \%)$ cases for ELCA use. $30(60 \%)$ of the procedures were performed via radial access. The 0.9 $\mathrm{mm} \mathrm{X-80} \mathrm{catheter} \mathrm{was} \mathrm{used} \mathrm{in} 41(82 \%)$ of cases, delivering on average $9000 \pm 3929$ pulses. ELCArelated complications included 2 coronary dissections and 1 perforation, all of which were covered with stents. No major complications could be directly attributed to the use of ELCA. There was one death and one case of stent thrombosis within 30 days of the procedure.

Conclusion ELCA can be performed safely via the radial approach with a $0.9 \mathrm{~mm}$ catheter with a high success rate by suitably trained operators. The low procedure-related complications with contemporary techniques make this a very useful tool for complex coronary interventions, especially for difficult to dilate lesions and chronic total occlusion vessels.

\section{Key questions}

What is already known about this subject?

- Coronary laser atherectomy is a useful but underused treatment modality in treatment of calcified difficult to cross lesions.

- There have been mixed earlier reports of success with this modality and relatively high procedural complications mostly with the bulky $1.4 \mathrm{~mm}$ laser catheter.

What does this study add?

- Our work shows that laser atherectomy via radial approach using $0.9 \mathrm{~mm}$ laser catheter is safe and convenient with good periprocedural outcomes.

How might this impact on clinical practice?

- These results are expected to encourage other centres involved in complex coronary intervention to take up coronary laser atherectomy more frequently in calcified, difficult to dilate lesions and chronic total occlusions.

\section{INTRODUCTION}

Percutaneous coronary intervention (PCI) in patients with heavily calcified vessels is challenging. Severely calcified lesions account for up to $12 \%$ of patients undergoing coronary angiography ${ }^{1}$ and can prevent the crossing of balloons and even wires. Even if the lesion can be crossed with a wire, calcified or heavily fibrotic plaques may resist high-pressure noncompliant balloon inflations and cutting balloons. Attempting stent implantation within such lesions risk stent malapposition, underdeployment and increase risk of coronary dissection, perforation and stent 


\begin{tabular}{|c|c|}
\hline Variable & Mean $( \pm S D)$ number $(\%)$ \\
\hline Age, years & $67.9( \pm 11.4)$ \\
\hline \multicolumn{2}{|l|}{ Gender } \\
\hline Male & $32(65.3 \%)$ \\
\hline Female & $17(34.7 \%)$ \\
\hline $\mathrm{BMI}, \mathrm{kg} / \mathrm{m}^{2}$ & $29.1( \pm 5.8)$ \\
\hline Previous CVA & $2(4.1 \%)$ \\
\hline Peripheral vascular disease & $4(8.2 \%)$ \\
\hline Non-cardiac surgery & $2(4.1 \%)$ \\
\hline Previous MI & $23(46.9 \%)$ \\
\hline Previous CABG & $11(22.4 \%)$ \\
\hline Previous PCl & $24(29 \%)$ \\
\hline \multicolumn{2}{|l|}{ Diabetes } \\
\hline Not diabetic & $27(55.1)$ \\
\hline Diet controlled & 1 (2) \\
\hline Oral medicine & $12(24.5)$ \\
\hline Insulin dependent & $9(18.4 \%)$ \\
\hline \multicolumn{2}{|l|}{ Clinical syndrome } \\
\hline Stable angina & $25(50 \%)$ \\
\hline UA/NSTEMI & $17(34 \%)$ \\
\hline STEMI & $8(16 \%)$ \\
\hline $\begin{array}{l}\text { Cardiogenic shock } \\
\text { (consequence of STEMI) }\end{array}$ & $3(6 \%)$ \\
\hline
\end{tabular}

Target vessel

\begin{tabular}{|lc|}
\hline LMS/LAD & $21(42 \%)$ \\
\hline LCX/RCA & $26(52 \%)$ \\
\hline SVG & $3(6 \%)$ \\
\hline Procedure urgency & \\
\hline Elective & $23(46 \%)$ \\
\hline Urgent & $19(38 \%)$ \\
\hline Emergency & $8(16 \%)$ \\
\hline LV function & \\
\hline Good (EF $>50 \%)$ & $31(63.3)$ \\
\hline Moderate (EF 30\%-50\%) & $8(16.3)$ \\
\hline Poor (EF <30\%) & $4(8.2)$ \\
\hline Unknown & $6(12.2)$ \\
\hline Diagnostic devices & \\
\hline None & $38(76 \%)$ \\
\hline IVUS/OCT & $7(14 \%)$ \\
\hline Pressure wire & $2(4 \%)$ \\
\hline Procedural indications & \\
\hline Heavily calcified lesion & $22(44 \%)$ \\
\hline CTO (failure to cross) & $10(20 \%)$ \\
\hline High thrombus burden & $11(22 \%)$ \\
\hline In-stent restenosis & $7(14 \%)$ \\
\hline 6 Fr guide catheter & $41(82 \%)$ \\
\hline & \\
\hline
\end{tabular}

Continued
Table 1 Continued

\begin{tabular}{lc} 
Variable & Mean (土SD) number (\%) \\
\hline Arterial access & \\
Radial (right/left) & $30(60 \%)$ \\
Femoral & $16(32 \%)$ \\
Combined (radial/femoral) & $4(8 \%)$ \\
Glycoprotein Ilb/llla (eptifibatide) & $8(16 \%)$ \\
\hline
\end{tabular}

$\mathrm{BMI}$, body mass index; CABG, coronary artery bypass grafting; CTO, chronic total occlusion; EF, ejection fraction; IVUS, intravascular ultrasound; LAD, left anterior descending artery; LCX, left cercumflex artery; LMS, left main stem; LV, left ventricle; $\mathrm{MI}$, myocardial infarction; NSTEMI, non-ST-elevation myocardial infarction; OCT, optical coherence tomography; PCI, percutaneous coronary intervention; RCA, right coronary artery; STEMI, STelevation myocardial infarction; SVG, saphenous vein grafts; UA, unstable angina.

thrombosis. Specialised techniques and equipment are therefore required for such cases.

Atheroablation by excimer laser coronary atherectomy (ELCA) can be helpful in these circumstances. Excimer lasers use a mixture of rare gas and halogen to generate brief pulses of high-frequency ultraviolet (UV) light. The UV laser can disrupt hard atherosclerotic plaque through several mechanisms, including breaking molecular bonds (photochemical), plaque cell rupture by heat generated at the catheter tip (photothermal) and disruption of intravascular material as vapour bubbles rapidly expand and implode (photomechanical). ${ }^{2}$ The fragments released are small $(<10 \mu \mathrm{m})$ and thus do not obstruct the coronary microcirculation. ${ }^{3}$ The short wavelength $(308 \mathrm{~nm})$ ensures minimal penetration of thermal energy beyond the intended target.

Compared with rotational atherectomy (RA), excimer catheters offer unique advantages including a short monorail segment, easing delivery over a standard 0.014" guidewire. Additionally, the most widely used $0.9 \mathrm{~mm}$ $\mathrm{X}-80$ catheter is deliverable via a 6 Fr guide catheter, allowing ELCA to be performed via the radial approach. However, severely calcified plaques may require treatment with both ELCA and RA in combination, referred to as a 'RASER' procedure. ${ }^{4}$

Laser atherectomy has been used as an adjunct to percutaneous coronary intervention since the early 1980 s. ${ }^{5}$ Early studies have documented high complication rates and restenosis. ${ }^{6}$ However, these studies predate the introduction of the smaller $0.9 \mathrm{~mm}$ catheter, which is now the most frequently used laser catheter for coronaries. ${ }^{7}$ Although the efficacy of ELCA has been assessed in a variety of clinical cohorts, there is a paucity of clinical outcome data in a real-world mixture of patients presenting with and without acute myocardial infarction. In this study, we present indications, procedural characteristics, complications and outcomes of ELCA in a contemporary coronary interventional practice in a single large quaternary UK hospital over 6 years. 


\begin{tabular}{|c|c|c|c|}
\hline Variable & Mean ( \pm SD) number (\%) & Variable & Mean ( $($ SD) number (\%) \\
\hline \multicolumn{2}{|c|}{ Size of laser catheter (mm) } & \multicolumn{2}{|l|}{ Fluence } \\
\hline 0.9 & $41(82 \%)$ & 80 & $16(32 \%)$ \\
\hline 1.4 & $3(6 \%)$ & $40-80$ & $13(26 \%)$ \\
\hline Unknown & $6(12 \%)$ & Unknown & $21(42 \%)$ \\
\hline \multicolumn{2}{|l|}{ Frequency $(\mathrm{Hz})$} & Adjunctive rotational atherectomy & $11(22 \%)$ \\
\hline 80 & $18(36 \%)$ & \multicolumn{2}{|l|}{ Size of burr } \\
\hline $40-80$ & $12(24 \%)$ & $1.25 \mathrm{~mm}$ & $4(8 \%)$ \\
\hline Unknown & $20(40 \%)$ & $1.5-2 \mathrm{~mm}$ & $5(10 \%)$ \\
\hline Number of pulses & $9000( \pm 3929)$ & $>2 \mathrm{~mm}$ & $2(4 \%)$ \\
\hline
\end{tabular}

$\mathrm{Hz}$, Hertz; mm, Millimeter.

\section{METHODS}

\section{Study population}

Fifty consecutive patients treated with ELCA from 1 January 2013 to 31 January 2019 at the Queen Elizabeth Hospital, Birmingham, UK. Patients were identified using a prospectively maintained British Cardiovascular Interventional Society database.

As it was an all comers cohort, the indications ranged from elective PCI in the setting of stable angina to emergency acute coronary syndromes with cardiogenic shock without any exclusion criteria. Laser was used if the lesion was angiographically assessed as heavily calcified and the inability of the smallest balloon or microcatheter to cross the lesion. For those lesions that were assessed with intravascular ultrasound or optical coherence tomography, laser was used if the imaging suggested a very high thrombus burden or in calcified lesions a $\geq 270$ degree of calcium arc, with $\geq 0.5 \mathrm{~mm}$ thickness and $\geq 40 \mathrm{~mm}$ of length of calcified lesion.

\section{Outcomes}

Immediate procedural success was defined as thrombolysis in myocardial infarction (TIMI) III flow in the target vessel with $<50 \%$ pre-angioplasty luminal stenosis. Major adverse cardiac and cerebrovascular event (MACCE) were defined as all-cause death, myocardial infarction or stroke and was recorded during hospital stay and at 30-day follow-up.

\section{ELCA procedure details}

The excimer laser system (Spectranetics CVX-300) uses xenon chloride medium to generate UV light and produces a monochromatic single wavelength-308 nm fluence of $20-80 \mathrm{~mJ} / \mathrm{mm}^{2}$ and pulse repetition rate of $40-80 \mathrm{~Hz}$. Vascular access was obtained using 6 or $7 \mathrm{Fr}$ sheaths in the radial or femoral arteries. In some cases, both radial and femoral access were required. The laser catheter used was of $0.9 \mathrm{~mm}$ or $1.4 \mathrm{~mm}$ in diameter. Saline flush and bathe technique was used to clear the blood and dye during delivery of the therapy and the catheter was advanced in small increments with $10 \mathrm{~s}$ bursts of lasing.

\section{RESULTS \\ Baseline characteristics}

Patients had a mean age of $67.9 \pm 11.4$ years and a male preponderance $32 / 50(64 \%)$. The majority of patients $(72 \%)$ had previous revascularisation with either PCI or coronary artery bypass grafting. Twelve $(24 \%)$ patients had adjuvant coronary fractional flow reserve/coronary imaging at the same time. Twenty-three $(46 \%)$ patients were treated electively and $8(16 \%)$ patients were treated as emergencies for ST-elevation MI, among whom $3(6 \%)$ patients were in cardiogenic shock. Laser atherectomy was used as an adjuvant to coronary RA in $11(22 \%)$ cases and thrombus aspiration was performed in $6(12 \%)$ patients. Glycoprotein IIb/IIIa inhibitor was used in eight (16\%) cases. Thirty $(60 \%)$ cases were performed by radial (left/ right) approach without the need to change the access site. Only $16(32 \%)$ cases were performed via the femoral approach and a further $4(8 \%)$ used both radial and femoral approach. One of the main indications of ELCA was the failure of balloon tracking due to a calcified lesion or chronic total occlusion (CTO) occurred, which was seen in $32(64 \%)$ cases (table 1$)$.

\section{Laser technical data}

The majority of cases $(82 \%)$ were performed using the $0.9 \mathrm{~mm}$ diameter ELCA catheter. A frequency of $80 \mathrm{~Hz}$ was used in $18(36 \%)$ cases and 40-80 Hz in another 12 (24\%) cases. The data were not available for the rest of the cases. The mean number of laser pulses were $9000 \pm 3929$ (table 2).

\section{Procedure outcomes}

There were no periprocedural complications in 46 (92\%) patients (figure 1). Laser atherectomy was successful in crossing all uncrossable lesions where the smallest balloon or microcatheter could not cross. A coronary perforation occurred in one case and was treated by a covered stent. The perforation was attributed to use of RA. Two cases of coronary dissection were seen and were treated successfully with a drug-eluting stent. These complications were not directly attributable to the use of ELCA. 


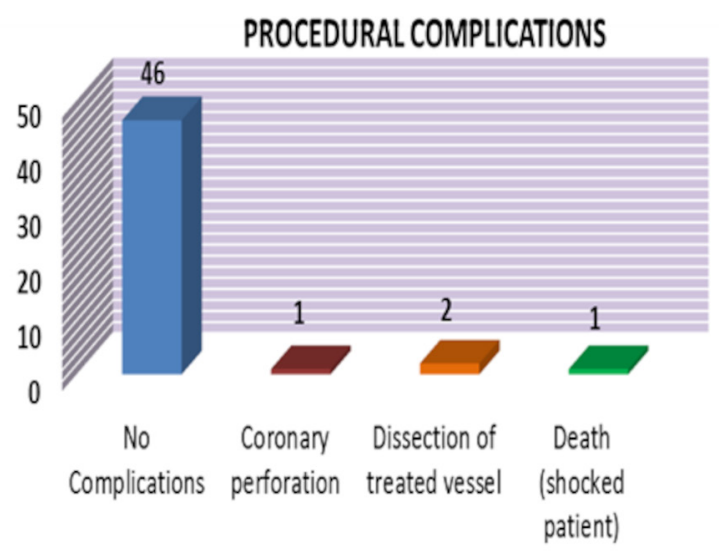

Figure 1 Immediate periprocedural complications while the patient was in the cardiac catheter lab.

One death occurred during the procedure in a patient with cardiogenic shock in the context of a late presenting MI. Apart from one mortality, all patients had immediate procedural success with $<50 \%$ residual stenosis and TIMI III flow in the target vessel. The mean stented segment length was $41 \mathrm{~mm}$ (SD $9 \mathrm{~mm}$ ) and diameter was $3.1 \mathrm{~mm}$ (SD $4.2 \mathrm{~mm}$ ). Within 30 days of the procedure, there was one transient ischaemic attack and one stent thrombosis leading to MI and both these patients made full recovery (table 3).

\section{DISCUSSION}

This study documents the 6-year experience of a single large quaternary centre using ELCA to treat non-crossable, heavily calcified coronary artery lesions. Presence of CTO and very calcified lesion was the main indication in about two-thirds of the cases in our cohort. The results from this retrospective study found that ELCA was associated with high rates of procedural success and low rates of periprocedural complications. The majority of PCI procedures are performed via the radial artery and on finding non-crossable lesions, ELCA can be performed without the need for changing access site. While previous studies report up to $48 \%{ }^{4}$ transradial ELCA, in this study $60 \%$ of cases were performed via the transradial approach alone without compromising success or complication rate.

This study demonstrates a low rate of coronary dissection compared with other studies. In trials excluding patients with acute MI, the rate of angiographic dissection

Table 3 30-Day MACCE (for death, myocardial infarction and stroke/TIA)

\begin{tabular}{ll}
\hline Variable & N (\%) \\
\hline No complication & $47(94 \%)$ \\
\hline Death & $1(2 \%)$ \\
Myocardial infarction (subacute stent thrombosis) & $1(2 \%)$ \\
\hline TIA & $1(2 \%)$ \\
\hline
\end{tabular}

MACCE, major adverse cardiac and cerebrovascular event; TIA, transient ischaemic attack. following ELCA use has been reported as up to $13 \% .^{8}$ In another study of 151 post-MI patients treated with ELCA, ${ }^{9}$ major dissection occurred in $5 \%$ of cases, compared with only $2 \%$ in the present study. Other studies have corroborated that low rates of coronary dissection can be achieved. The multicentre CORAL trial demonstrated that the procedural success of ELCA in the treatment of patients with saphenous vein grafts was lower $(82 \%)$ than comparative studies in native coronary vessels, however, the rate of major dissection was just under $1 \%$ and lower 30-day MACE as compared with control population from theSaphenous vein graft Angioplasty Free of Emboli Randomized (SAFER) trial. ${ }^{10}$

With an ageing population, heavily calcified coronary lesions and in-stent restenosis (ISR) are likely to be encountered with increasing frequency. ELCA is expected to become more widely adopted over time. The use of ELCA to treat patients with ISR has been assessed in several studies. Applying laser to five types of stainlesssteel coronary stents did not impact stent endurance or release significant particulate matter. ELCA in the setting of ISR has similar rates of procedural success, complications and long-term clinical outcomes as balloon angioplasty alone,${ }^{11}$ and RA. ${ }^{12}$ The combination of ELCA and balloon angioplasty produces greater stent expansion than balloon angioplasty alone. ${ }^{13}$

While RA remains the main treatment modality for heavily calcified lesions, it relies on a 0.009-inch RotaWire be advanced distal to the lesion. Case series have demonstrated that RASER can facilitate revascularisation where the RotaWire could not traverse the lesion. ${ }^{4}$ In this study, ELCA was combined with RA in $22 \%$ of cases, which is higher than previous work by Badr et al. ${ }^{14}$

\section{Limitations}

ELCA is a specialised coronary adjunctive treatment which is performed only in a relatively small number of centres with expertise. This retrospective study is therefore limited by the small number of ELCA procedures performed despite assessing a 6-year timeframe. Furthermore, while 30-day MACCE data are presented, longterm data have not been compiled. Another limitation has been the relatively low use of intracoronary imaging used. This could be explained by the presence of some cases with acute MI and high thrombus burden in which flow restoration and clinical stability was the first priority of management. Moreover, the accepted standard of use of intracoronary imaging in the highly calcified vessels was not as widespread in the earlier half of the dataset.

\section{CONCLUSIONS}

ELCA can be performed safely via the radial approach in most patients with a $0.9 \mathrm{~mm}$ catheter with a high success rate. The low procedure-related complications with contemporary techniques make this a very useful tool for complex coronary interventions, especially for difficult to dilate lesions or CTO vessels. 
Twitter Muhammad Jawad-UI-Qamar @Jawadulqamar and Mohammed Osheiba @mosheiba

Acknowledgements We thank the broader cardiology team at the Queen Elizabeth hospital for their help in the clinical cases included in the manuscript.

Contributors SQK started the original idea and supervised the project. MJUQ collated the data and performed the original analysis. MJUQ, HS, SQK and VV drafted the paper. SQK, KS, PFL, JNT, SND, MO and AZ provided expert review of the paper, especially in the methods, results and discussion.

Funding The authors have not declared a specific grant for this research from any funding agency in the public, commercial or not-for-profit sectors.

Competing interests None declared.

Patient consent for publication Not required.

Ethics approval The British Cardiovascular Interventional Society (BCIS) formally collects the data for all coronary interventional procedures performed in the UK with regard to the clinical characteristics, procedural details and outcomes as part of a robust National Institute of Cardiovascular Research (NICOR) audit. The mortality data are tracked with the help of Office of National Statistics using the linked National Health Service number for patients in England and Wales. As all data collected as part of the BCIS database is managed by the NICOR registry as part of the national audit initiative and is anonymised for purposes of research, hence, a formal local ethical approval is not needed.

Provenance and peer review Not commissioned; externally peer reviewed.

Data availability statement All data relevant to the study are included in the article. Original dataset is available on reasonable request.

Open access This is an open access article distributed in accordance with the Creative Commons Attribution 4.0 Unported (CC BY 4.0) license, which permits others to copy, redistribute, remix, transform and build upon this work for any purpose, provided the original work is properly cited, a link to the licence is given, and indication of whether changes were made. See: https://creativecommons.org/licenses/by/4.0/.

\section{ORCID iDs}

Muhammad Jawad-UI-Qamar http://orcid.org/0000-0001-6336-0327

Harish Sharma http://orcid org/0000-0002-0525-3520

Vincenzo Vetrugno http://orcid.org/0000-0002-1765-8146

Peter F Ludman http://orcid.org/0000-0002-7237-0946

Sohail Q Khan http://orcid.org/0000-0001-9951-4885

\section{REFERENCES}

1 Mintz GS, Popma JJ, Pichard AD, et al. Patterns of calcification in coronary artery disease. A statistical analysis of intravascular ultrasound and coronary angiography in 1155 lesions. Circulation 1995;91:1959-65.

2 Oraevsky AA, Jacques SL, Pettit GH, et al. XeCl laser ablation of atherosclerotic aorta: optical properties and energy pathways. Lasers Surg Med 1992;12:585-97.

3 Rawlins J, Din JN, Talwar S, et al. Coronary intervention with the excimer laser: review of the technology and outcome data. Interv Cardiol 2016;11:27-32.

4 Fernandez JP, Hobson AR, McKenzie D, et al. Beyond the balloon: excimer coronary laser atherectomy used alone or in combination with rotational atherectomy in the treatment of chronic total occlusions, non-crossable and non-expansible coronary lesions. Eurolntervention 2013;9:243-50.

5 Lee G, Ikeda RM, Kozina J, et al. Laser-dissolution of coronary atherosclerotic obstruction. Am Heart J 1981;102:1074-5.

6 Baumbach A, Bittl JA, Fleck E, et al. Acute complications of excimer laser coronary angioplasty: a detailed analysis of multicenter results. J Am Coll Cardiol 1994;23:1305-13.

7 Bittl JA, Chew DP, Topol EJ, et al. Meta-analysis of randomized trials of percutaneous transluminal coronary angioplasty versus atherectomy, cutting balloon atherotomy, or laser angioplasty. J Am Coll Cardiol 2004;43:936-42.

8 Litvack F, Eigler N, Margolis J, et al. Percutaneous excimer laser coronary angioplasty: results in the first consecutive 3,000 patients. The ELCA Investigators. J Am Coll Cardiol 1994;23:323-9.

9 Topaz O, Ebersole D, Das T, et al. Excimer laser angioplasty in acute myocardial infarction (the CARMEL multicenter trial). Am J Cardiol 2004;93:694-701.

10 Giugliano GR, Falcone MW, Mego D, et al. A prospective multicenter registry of laser therapy for degenerated saphenous vein graft stenosis: the COronary graft Results following Atherectomy with Laser (CORAL) trial. Cardiovasc Revasc Med 2012;13:84-9.

11 Giri S, Ito S, Lansky AJ, et al. Clinical and angiographic outcome in the laser angioplasty for restenotic stents (LARS) multicenter registry. Catheter Cardiovasc Interv 2001;52:24-34.

12 Mehran R, Dangas G, Mintz GS, et al. Treatment of in-stent restenosis with excimer laser coronary angioplasty versus rotational atherectomy: comparative mechanisms and results. Circulation 2000;101:2484-9.

13 Mehran R, Mintz GS, Satler LF, et al. Treatment of in-stent restenosis with excimer laser coronary angioplasty: mechanisms and results compared with PTCA alone. Circulation 1997;96:2183-9.

14 Badr S, Ben-Dor I, Dvir D, et al. The state of the excimer laser for coronary intervention in the drug-eluting stent era. Cardiovasc Revasc Med 2013;14:93-8. 